\title{
Scientific writing: Need of the day
}

\section{Reetu Baral MD}

The reasons for scientific writing range from noble to base reasons. Some authors write for pleasure derived from the creative activity of writing and from sharing one's intellectual pursuits. For many authors, writing is a channel for expressing the joy of scientific discovery. At the bottom of the list, writing may be considered by some to be a chore where getting published is a 'necessary evil' in order to fulfill certain specific minimum requirements, e.g. for getting a job or a promotion.

Well trained physicians are to be judged not by their knowledge or their outlook upon present problems, but by their ability to deal with new ones. Many physicians hesitate to try their hand at research and writing because they feel that they are not scientists or authors. Actually, the scientific techniques in writing and research can be learned and used successfully like other manual skills. This ability will grow with the application and the versatility acquired with experience.

A published article is indisputable evidence of research that has been performed, completed, and accepted by peers. A publication is also an indicator of achievement of a certain academic standard. Besides communication of a finalized piece of research, the written work is the basis for further opinions, views and critiques from fellow professionals and academics separated by time and distance. Most importantly, it represents the only permanent record of scientific work that has been completed.

For pathologists, the benefits of scientific writing can be grouped into the following headings:

- Career

- Professional

- Practical

- Pathologist-specific

\section{Career benefits}

The most compelling reason for many doctors to start writing is to fulfill specific job requirements by employers (e.g. universities). These include initial appointment to an academic position or promotion. The trend of universities asking for research papers for promotion has both advantage and disadvantage. The advantage being more of our colleagues will be coming up with research and papers for publications. We will have many documented studies done in our own country, written in our own context, being done in the same constraints that we face everyday. Rather than referring to a similar study done in an advanced laboratory in a developed country we can refer to the one done in our own labroratories. But the disadvantage of this is that more and more superficially written papers will be produced, which may not give exact or reliable data. Many ghost authors will be seen in the name of writing papers for promotions.

\section{Professional benefits}

For young doctors, having published articles in reputable journal is a great help when applying for positions for fellowships. For more established doctors, publications enable them to gain recognition and acknowledgement as experts in a particular field at national and international levels. Invitations to lecture at scientific meetings and to be reviewer and editorial board members, are among the benefits of this enhanced professional reputation. The discipline imposed by scientific study, research and writing increases the depth of knowledge in the subject being investigated. This knowledge sharpens clinical skills and facilitates teaching of students and postgraduates. Through scientific writing and publication, the author achieves expertise and eventually becomes acknowledged as an authority by academic peers. 


\section{Practical benefits}

One has to have training to be discriminatory and critical while preparing the manuscript. Scientific writing entails the discipline of performing a complete literature search, gathering and analyzing data, and writing and revising numerous versions of a manuscript. Following the satisfaction of having their own manuscripts accepted, authors will be better positioned to appreciate what is written in journals and other scientific publications. With the huge amount of information available on the internet journals and other printed materials, it is vital for all professionals and academics to be able to judge the quality and reliability of published work. Patients always want to be seen by the most knowledgeable and up-to-date doctor.

\section{Pathologist-specific benefits}

Most clinicians do not have in-depth knowledge of or formal training in, clinical and histopathological techniques, so they may be compelled to move into our arena, if we are not providing the service to their requirements and satisfaction. To be a successful pathologist communication with the clinicians is essential. Unlike most of our clinical colleagues, our 'clients' are not laypersons but highly-qualified doctors, usually specialists and sub-specialists. Pathologists are often referred to as the 'doctor's doctor', and must therefore work hard to live up to this moniker. Written communication is an integral part of daily pathology practice. Pathologists are judged by their reports, in terms of style, accuracy and completeness. The reports should be of practical usefulness, contributing to the diagnosis and management of patients. As the pathology reports may also be read by peers from other institutions, they should be clear, concise and written in a universally understood format. Being proficient in scientific writing is therefore a necessity if one aims to be a competent pathologist.

Writing is the most important means for communicating scientific work. Research and publication complement teaching and training, clinical service and patient care. There are many reasons for writing, one of the most important of which is the inherent training undertaken to better appreciate and evaluate the published work of others. Effective scientific writing is an important component of a pathologist's practice. Trainees should be encouraged to start early, and senior members of our profession should act as role models and provide support.

\section{REFERENCES}

1. International Committee of Medical Journal Editors (ICMJE) www. ICMJE.org

2. World Association of Medical Editors www.WAME.org

3. Council of Science Editors www.councilofscienceeditors 